\title{
Tritrophic Effect of Metarhizium anisopliae on Wheat Aphids and its Parasitoids
}

\author{
Hafiz Sultan Sulahudin*, Asif Javed, M Jalal Arif and M Dildar Goggi \\ University of Agriculture Faisalabad, Pakistan \\ *Corresponding Author: Hafiz Sultan Sulahudin, University of Agriculture \\ Faisalabad, Pakistan.
}

DOI: $10.31080 /$ ASAG.2020.04.0813
Received: January 30, 2020

Published: February 26, 2020

(c) All rights are reserved by Hafiz Sultan

Sulahudin., et al.

\begin{abstract}
The present experiment was conducted to evaluate the tritrophic effect of Metarhizium anisopliae on wheat aphids and its parasitoids. The experiment consisted of ten treatments having seven concentrations (1 ppm, $2 \mathrm{ppm}, 4 \mathrm{ppm}, 8 \mathrm{ppm}, 16 \mathrm{ppm}, 32 \mathrm{ppm}$ and $64 \mathrm{ppm}$ ) of M. anisopliae and field recommended doses of confidor (Imidacloprid) + Hombre (Febuconazole + Imidacloprid) and control. No aphid infestation was observed during the 1st week of December to the 2nd week of the February. 1.5 aphids/tiller were observed where Hombre, Confidor and M. anisopliae at the rate of 64 ppm, 32 ppm and 16 ppm were applied. Maximum aphid population (10.5/tiller) was observed in the control area than the treated plots. M. anisopliae application at the rate of $1 \mathrm{ppm}, 2 \mathrm{ppm}, 4 \mathrm{ppm}$ and 8 ppm demonstrated $64.0 \%, 64.50 \%, 64.55 \%$ and $64.51 \%$ percent adult emergence of aphids. Seed treatment method was found statistically more effective (3.8 aphids/tiller) than root dip method (3.0 aphid/tiller).

Keywords: Beauveria bassiana; Confidor; EPF; Imidacloprid; IPM; Metarhizium anisopliae; Shizaphis graminum; Triticum aestivum
\end{abstract}

\section{Introduction}

Wheat is directly consumed by the human beings in variety of products directly or indirectly since the beginning of human being. With the passage of time the climate change and increase in the pest population the wheat is facing serious threat of damage. One of these serious threat is wheat aphid which has become an emerging issue for the whole world.

\section{Objectives}

The objectives of my research are as follows

1. To control the wheat aphid below economic threshold level

2. To find an alternative source of control for aphid instead of pesticides

3. To increase the production of wheat by reducing pest population

4. To discourage the use of pesticides on staple diets like wheat.

Wheat (Triticum aestivum L.) is also called as" king of cereals" is an important cereal crop and worldwide occupies the $17 \%$ of cultivated lands. It provides $20 \%$ calories to human beings is the most popular staple food of the people worldwide. It is the cheapest and excellent source of minerals, fibers, vitamins and proteins [1,2]. In global grain production its share is $30 \%$ (Khanzada., et al. 2012). Pakistan economy is agriculture based, where wheat occupies the central position. Wheat contribution to value added in agriculture and to GDP is $9.9 \%$ and $2.0 \%$ respectively. During 2015-16, wheat was cultivated on an area of 9260 thousand hectare as compared to last year 9204 hectares with an increase of $0.6 \%$. Wheat production during 2015-16 was 25.482 million tones over the last year production of 25.086 million tones with an increase of $1.6 \%$ over the last year (Anonymous, 2015-16). Many biotic and abiotic factors lower the crop yield such as varieties, cultivation method, irrigation and insect pest and disease attack. Globally these environmental factors lower the production of agricultural crops. Wheat yield is decreased due to many factors like drought, heat, chilling, salinity, freezing and attack of insect pests and diseases (Abbas, 2012). Wheat attacking insect pests belong to eight orders of insect pests which include Hymenoptera, Diptera, Orthoptera, Coleoptera, Lepidoptera, Hemiptera, Homoptera and few species of mites [3]. Among them the order Homoptera which includes the sucking insects especially wheat aphid, Schizaphis graminum (Homoptera: Aphididae) are most divesting insect among all of these [4]. But Diuraphis noxia now has become serious wheat pest in Pakistan. It attacks at early stage of the crop and prevails whole cultivation season of wheat [5]. In early stage attack, embryo development reduces which causes reduction in grain formation also reduces grain weight (Zachvatkin, 1941) as a result loss its viability [6]. Wheat aphids (Schizaphis graminum) is a major pest of leguminous produces and start direct loss by phloem cell fluid ingestion, and indirectly by transmitting virus and other pathogens. Severe damage causes less grain per ear and results in low yield of the crop. The aphid is small greenish brown soft bodied insect pest that damage the upper and lower surface of the foliage and imbibe the cell liquid. Heavy incursion results in stunted plants growth, plants become dry, foliage twisting occur, and decease of new vegetation. Photosynthetic activity affects due to the black sooty mold growth on the honeydew excreted by aphid which falls on the lower leaves of plants [7]. Direct and indirect losses caused by aphid are $10-50 \%$ and $20-80 \%$ respectively [8]. Aphid cause losses of 8.4, $28.8,41.9,27.3$ and $3.08 \%$ in plant height, ear number, grain num- 
ber, grain yield and 1000 grain weight respectively (Rajesh., et al. 1995). One aphid reduce wheat grain yield $2.20 \%$ [9]. $72 \%$ damage was directly due to aphid sucking and rest was due to fungi [10]. 30 - 40\% reduction in grain yield was recorded at 15 aphids per tiller [11]. Aphids are controlled by the application of commonly used insecticides but these are injurious for human, animal health, development of resistance in insects and cause environmental pollution. Alternative control methods like trick barriers of the crop, intercropping and biological control are used in many crops [12,13].

Among microbial control entomopathogenic fungi are of great importance as they are target specific and cause no harm to humans [14]. These are environmental friendly and reduce the use of conventional insecticides [15]. Entomopatho. fungi use as microbial insecticides against aphid has been very effective [16]. Entomopathogenic fungus spores germinate on the host cuticle and occupy the host [17]. M. anisopliae has been screened for its compatibility with insecticides [18]. Study of virulence of Metarhizium anisopliae strains against mustard aphid showed that the strain PDRL711 was found less effective whereas strains PDRL738 was found a virulent. However, strain PDRL526 showed as increase in efficacy from 72 to $83 \%$ and strain PDRL711 from 44 to $70 \%$. The results promised the control of aphid with M. anisopliae application [19].

Keeping in view the entomopathogenic fungus importance for the control of insect pests this study was arranged to assess the tritrophic effect of Metarhizium anisopliae on wheat aphid and its parasitoids.

\section{Materials and Methods}

Experiment was conducted with the following material and methods.

\section{Site selection}

Experiment was conducted at the Entomological research area Young wala, University of Agriculture Faisalabad during $15^{\text {th }}$ November to $10^{\text {th }}$ April 2017.

\section{Seed variety}

Seed of a good recommended variety (Galaxy 2013) was purchased from AARI (Ayub agriculture research institute, Faisalabad).

\section{Land preparation}

All the agronomic practices were done for the land preparation. First of all ploughing was done with the help of tractor and chisel plough. After this irrigation (Rouni) was done with the enough water. On water condition 2 to 3 deep ploughing were done followed by a planer to pulverize the soil.

\section{Sowing}

Sowing was done with the help of drill on $15^{\text {th }}$ November, 2017. Proper P x P and R x R distance was maintained.

\section{Insect culture}

Schizaphis graminum colonies were maintained on the wheat (Triticum aestivum) plants grown in the plastic pots containing sterilized potting mixture (a mixture of sand-peat and black clay soil in 1:1 ratio). Recommended irrigation schedule was followed.

\section{Fungal culture}

Fungus Metarhizium anisopliae was bought from the market i. e. Pacer $^{\circledR}$, Agri life, India. It was applied to the crop through the different application techniques such as root dip method, seed dressing, foliar application and bed treatment in the field as well as in the pots under natural conditions.

\section{Root dip method}

When the wheat crop roots have enough developed to be treated with the fungus then, Metarhizium anisopliae fungal solution was applied to the crop roots. After treatment with the fungus the crop was transplanted to the main field from the nursery.

\section{Seed dressing}

Metarhizium anisopliae fungus (powder form) was mixed in the water thoroughly (as recommended). Seed was soaked in the solution for 5 hours. Then the soaked seeds were dried and sown in the field.

\section{Foliar application}

It is a technique of direct feeding liquid fertilizer through their leaves to the plants. Essential elements are absorbed by the plants. Essential elements are absorbed the plants epidermis and the stomata. Metarhizium anisopliae fungus in the liquid form through the hand sprayer was sprayed on the crop.

\section{Aphid sampling}

Plot

One canal plot was selected to conduct the experiment. Plot was divided into three blocks dimensionally and each block was then further divided into six sub plots having 3/5ft dimensions. All the plots were treated with the fungus at different stages of the crop except one which was the control. Seven treatments were applied to the crop. One was the application of the insecticides (Confidor and hombre), second was the control treatment and the rest have been discussed above.

\section{Field trial}

Experimental design

Table

\section{Pots trial}

Wheat crop was also sown in the pots in the field and experiment was also carried out on them. Aphid nymphs and adults were carefully transferred to the each wheat plant. The no. of adults and nymphs were 15 and 15 respectively. Daily after the application the larvae and pupae were checked. When the insects were established on the wheat plants after the transfer of nymphs and adults, the plants were treated with the different concentrations of the fungus Metarhizium anisopliae and the insecticides. After the application data was recorded on weekly basis. 


\begin{tabular}{|c|c|c|c|c|c|c|}
\hline Block1 & Seed treatment & Root dip method & Bed treatment & Foliar application & $\begin{array}{c}\text { Confidor } \\
\text { (No application) }\end{array}$ \\
\hline Block2 & Confidor & $\begin{array}{c}\text { Control } \\
\text { (No application) }\end{array}$ & Seed treatment & Bed treatment & Root dip method & Foliar application \\
\hline Block3 & Bed treatment & Confidor & $\begin{array}{c}\text { Control } \\
\text { (No application) }\end{array}$ & Seed treatment & Foliar application & Root dip method \\
\hline
\end{tabular}

Table 1

Data collection

Data on observation basis was started taking from the 1st week of December till the crop harvesting on weekly basis. Data was taken of the aphid population density, nature and the level of the damage. Sub plots were randomly selected at each observation to count infested and healthy plants. Population of the aphid was counted by taking ten leaves randomly and then data was transformed into population change over time.

\section{Statistical analysis}

Aphid population data was transformed into population change over time. All the collected data was subjected to ANOVA technique to determine the significance parameters. Data was analyzed with the Tukey's HSD test with 5\% probability level to compare the means.

\section{Results and Discussion}

The present study was conducted to check the effect of Metarhizium anisopliae on wheat aphid and their parasitoids. Experiment was carried out in field as well as in pots. Ten treatments were used having seven concentrations of M. anisopliae ( $1 \mathrm{ppm}, 2 \mathrm{ppm}, 4 \mathrm{ppm}$, $8 \mathrm{ppm}, 16 \mathrm{ppm}, 32 \mathrm{ppm}$ and $64 \mathrm{ppm}$ ) field recommended dose of Confidor (Imidacloprid) and Hombre (Febuconazole + Imidacloprid) and a control. Treatments were also applied in the pots to check the effects. Following are the results of the experiment.

Regardless of method of application 0.0 deformed aphids was recorded in treatments where Hombre, Confidor, $M$. anisopliae at the rate of $64 \mathrm{ppm}, 32 \mathrm{ppm}$ and $16 \mathrm{ppm}$ were applied.

Saranya., et al. [20] studied that aphid mortality was increased with the increase in concentration of $M$. anisopliae.

This experiment indicates the potential of the entomopathogenic fungi as bio-control agent against the insect pest. Aphid is a sucking insect pest, suck the cell sap from the leaves and cause sooty mold. Conventional insecticides disturb the natural ecosystem and are harmful for the human and animal health. Insecticidal resistance is developed in the insects due to the conventional insecticides. Bio-pesticides are safe for human health and natural enemies. Present experiment was helpful for the safe management of the wheat aphid [21,22].

\section{Summery}

- $\quad$ There was no aphid infestation observed during the $1^{\text {st }}$ week of December to the second week of the February.

- $\quad$ Significant effect of the treatments was observed during the $3^{\text {rd }}$ week of the February in the field.
- 1.5 aphids/tiller were observed where Hombre, Confidor and Metarhizium anisopliae at the rate of 64 ppm, 32 ppm and 16 ppm were applied.

- Maximum aphid population (10.5/tiller) was observed in the control area than the treated plots.

- Seed treatment method was found statistically more effective (3.8 aphids/tiller) than root dip method (3.0 aphid/tiller).

- Application of M. anisopliae formulation at the rate of $1 \mathrm{ppm}$, $2 \mathrm{ppm}, 4 \mathrm{ppm}$ and $8 \mathrm{ppm}$ demonstrated infestation of $4.5,4.5$, 3.5 and 3.5 aphid/tiller.

- $0.0 \%$ deformed aphids were recorded in treatments where Hombre, Confidor, M. anisopliae at the rate of 64 ppm, 32 ppm and 16 ppm were applied.

- Application of M. anisopliae formulation at the rate of $1 \mathrm{ppm}$, $2 \mathrm{ppm}, 4 \mathrm{ppm}$ and $8 \mathrm{ppm}$ demonstrated infestation of $1.0 \%$, $1.72 \%, 4.29 \%$ and $6.0 \%$ deformed aphids.

- percent parasitism of aphids was recorded in treatments where Hombre, Confidor, M. anisopliae at the rate of $64 \mathrm{ppm}$, $32 \mathrm{ppm}$ and $16 \mathrm{ppm}$ were applied.

- Maximum aphid percent parasitism was recorded in control treatment (17.1 aphid/tiller).

- M. anisopliae application at the rate of $1 \mathrm{ppm}, 2 \mathrm{ppm}, 4 \mathrm{ppm}$ and 8 ppm demonstrated $64.0 \%, 64.50 \%, 64.55 \%$ and $64.51 \%$ percent adult emergence of aphids.

- Seed treatment method was found statistically more effective (3.28 aphids/tiller) than root dip method (0.0 aphid/tiller) during 4th week of February.

- Results of interaction indicates that comparatively the best aphid infestation (1 aphid/tiller) about 10 times less than control was observed in plots where Hombre, Confidor, $M$. anisopliae at the rate of $16 \mathrm{ppm}, 32 \mathrm{ppm}$ and $64 \mathrm{ppm}$ were applied by the root dip method.

- $\quad$ M. anisopliae application at the rate of $1 \mathrm{ppm}, 2 \mathrm{ppm}$ and 4 ppm and 8 ppm by root dip method demonstrated aphid infestation of 3 - 4 aphid/tiller (2.5 - 3 times less than the control (10.33 aphid/tiller).

- Control treatment exhibited the maximum aphid infestation (8.0\% deformity of aphids) in both application methods.

- M. anisopliae application formulation at the rate of $1 \mathrm{ppm}, 2$ ppm, 4 ppm and 8 ppm demonstrated infestation of 4.33, 4.33, 3.50 and 3.43 aphid/tiller in the pots application method. 
- $\quad$ Seed treatment method was found statistically more effective (3.5 aphids/tiller) than root dip method (3.0 aphid/tiller) in the pots application.

- Maximum aphid infestation was recorded in control treatment (9.50 aphid/tiller) in the pots.

- $\quad$ Seed treatment method was found statistically more effective (8.70 percent parasitism of aphid) than root dip method (6.02 percent parasitism of aphid) in the pots application method.

\section{Conclusion}

It was concluded that the use of $M$. anisopliae has good control on aphid population as compared to pesticides. Furthermore it is a better alternative of pesticides to control the wheat aphids which not only harm the environment but are also dangerous for human health as wheat is a staple food in most of the countries of the world. As already mentioned M. anisopliae was applied in different ways the foliar application showed best results of all the methods of applications regardless of the concentrations.

\section{Recommendations}

After this experiment I would recommend the following recommendations

- $\quad$ Discourage the use of conventional pesticides for wheat as much as possible

- Create awareness among the farmers about the importance of wheat and its utility

- Make the farmers aware of harmful effects of conventional pesticides on the environment and also on wheat which will lead drastic effects on human health

- Use of bio pesticides rather than conventional pesticides

- The government should take steps to increase easiness for the farmers for better production of wheat

- M. anisopliae must be made available in the market at affordable prices for the farmer.

\section{Bibliography}

1. Huang L., et al. "Map-based cloning of leaf rust resistance gene Lr21 from the large and polyploid genome of bread wheat". Genetics 164 (2003): 655-664.

2. Hammad G., et al. "Genetic analysis of quantitative yield related traits in spring wheat (Triticum aestivum L.)” (2013).

3. Hatchett A and H Webster. "Insect pests and mites of wheat". In: Wheat and wheat improvement (E. G. Heyne), Madison, Wisconsin, USA (1987): 625-668.

4. Aheer GM., et al. "Abiotic factors effect on population fluctuation of alate aphids in wheat". Journal of Agricultural Research 46.4 (2008): 367-371.
5. Aheer G., et al. "Abiotic factors effect on population fluctuations of alate aphids in wheat". Journal of Agricultural Research 8.7 (2008): 342-349.

6. Mahmood SH. "Mite fauna of stored grain seeds in central Iraq". Journal of Stored Products Research 28 (2012): 179-181.

7. Ryan JD., et al. "Greenbug and wheat: Model system for the study of phytotoxic". Homoptera 171-186.

8. Trdan S and L Mileroj. "The cereal aphid (Sitobion avenae T.). Wheat pest”. Sodobno-Kmetijstvo 32 (1999): 119-128.

9. Aheer GM., et al. "Role of weather in fluctuating aphid density in wheat crop". Journal of Agricultural Research 32.3 (1994): 295301.

10. Rebbinge R., et al. "Damage effects of cereal aphids in wheat". Netherlands Journal of Plant Pathology 187 (1981): 217-232.

11. Kieckhefer RW and JL Gellner. "Yield losses in winter wheat cause by low density cereal aphid population". American Society of Agronomy 84 (1992): 180-183.

12. Kumar R. "Insect pest control with special reference to African agriculture". Edward Arnold publishers, Michigan (1984): 455.

13. Thomas $M$ and J Waage. "Integration of biological control and host plant resistance breeding: A scientific and literature review tech". Center Agric. Rural Crop. Wageningen, Netherland (1996): 99.

14. Lacey LA., et al. "Insect pathogens as biological control agents: Do they have a future?" Biological control 21 (2001): 230-248.

15. Lacey LA and MS Goettel. "Current developments in microbial control of insect pests and prospects for the early 21st century". Entomophaga 40 (1995): 3-27.

16. Shah PA and JK Pell. "Entomopathogenic fungi as biological control". Applied Microbiology and Biotechnology 61 (2003): 413423.

17. Akbar SS., et al. "Compatibility of Metarhizium anisopliae with different insecticides and fungicides". African Journal of Microbiology Research 6.17 (2012): 3956-3962.

18. Asadi A., et al. "Genetic variation of the 20 bread wheat cultivar under chilling stress by using egg biplot analysis". International Journal of Agronomy and Plant Production 4.4 (2013): 696-706

19. Ujjan AA and S Shahzad. "Use of entomopathogenic fungi for the control of mustard aphid (Lipaphis erysimi) on canola (Brassica napusl.)". Pakistan Journal of Botany 44.6 (2012): 2081-2086. 
20. Saranya S., et al. "Efficacy of different entomopathogenic fungi against cowpea aphid, aphis craccivora". Journal of Biopesticides 3 (2010): 138-142.

21. Jandricic SE., et al. "Pathogenicity of conidia-based preprations of entomopathogenic fungi against the green house pest aphids Myzus persicae, Aphis gossypii and Aulacorthum solani (Hemiptera: Aphididae)". Journal of Invertebrate Pathology 118 (2014): 34-46.

22. Mahdavi., et al. "Susceptibility of the Hymenopteran parasitoid, Habrobracon hebetor (Braconidae) to the entomopathogenic fungi Beauveria bassiana Vuillemin and Metarhizium anisopliae Sorokin". Biological Control (2013): 17-20.

\section{Assets from publication with us}

- Prompt Acknowledgement after receiving the article

- Thorough Double blinded peer review

- Rapid Publication

- Issue of Publication Certificate

- High visibility of your Published work

Website: www.actascientific.com/

Submit Article: www.actascientific.com/submission.php

Email us: editor@actascientific.com

Contact us: +919182824667 